Nowoczesne Systemy Zarządzania

Zeszyt 12 (2017), nr 2 (kwiecień-czerwiec)

ISSN 1896-9380, s. 203-214

Modern Management Systems

Volume 12 (2017), No. 2 (April-June)

ISSN 1896-9380, pp. 203-214
Instytut Organizacji i Zarządzania

Wydział Cybernetyki

Wojskowa Akademia Techniczna

w Warszawie

Institute of Organization and Management Faculty of Cybernetics

Military University of Technology

\title{
Blogi w kreowaniu wizerunku marki
}

\section{Blogs in creating of brand image}

\author{
Joanna Wyrwisz \\ Politechnika Lubelska \\ j.wyrwisz@pollub.pl
}

\begin{abstract}
Abstrakt: Celem artykułu jest przedstawienie blogów jako ważnych obecnie narzędzi komunikacji marketingowej umożliwiających kreowanie wizerunku marek. Cyfryzacja procesów marketingowych sprawiła, iż blogi stały się efektywnym instrumentem komunikacji z otoczeniem. Zarówno blogi prywatne, jak i firmowe opierają się na tworzeniu i udostępnianiu treści. W odróżnieniu od typowego przekazu promocyjnego, blog nie ma charakteru perswazyjnego, a raczej informacyjny, edukacyjny czy rozrywkowy. Blogi wpisując się w model content marketingu, mogą skutecznie wpływać na odbiorców, formując oceny i pozycjonowanie produktów i marek. W artykule skoncentrowano się na blogach prywatnych o różnej tematyce, które z jednej strony jako medium społecznościowe, z drugiej jako narzędzie marketingu szeptanego mogą istotnie wpływać na percepcję i pozycjonowanie marek, budując ich rynkowy wizerunek. Słowa kluczowe: blog, media społecznościowe, komunikacja marketingowa, marka.
\end{abstract}

Abstract: The aim of the article is presenting blogs as important tools of marketing communication that are helpful in brand image creation. The digitization of marketing processes caused that blogs had become a new and effective instrument of the communication with the market. Both private, as well as company blogs are based on creating and sharing contents. Unlike the typical promotional form, the blog doesn't have coaxing but rather information, educational or entertainment character. Blogs, fitting perfectly in the model of content marketing, can effectively influence recipients by forming evaluations and positioning of products and brands. The article concentrates on private blogs that as the community medium as well as the tool of whispered marketing can indeed influence the perception and the positioning of brands building their market image.

Keywords: blog, social media, marketing communication, brand. 


\section{Wstęp}

Wraz ze zmieniającym się rynkiem zmieniają się możliwości komunikacji, wymiany informacji, a także dialogu z otoczeniem, a w szczególności z klientami. Otoczenie staje się bardziej dostępne, ale jednocześnie bardziej wymagające, gdyż zacierają się granice branż, powodując wzrost konkurencyjności. Firmy muszą śledzić te zmiany, by móc rozsądnie je wykorzystywać i wdrażać odpowiednie rozwiązania dla swoich odbiorców. Z drugiej strony konsumenci żyją aktualnie w środowisku o niemal nieograniczonych możliwościach, szczególnie jeśli chodzi o dostęp do informacji, przez co zmuszeni są do ciągłych wyborów, ocen i decyzji, które niejednokrotnie podejmowane są pod wpływem innych osób. (Blog (v) power, http). Rynek jest pełen różnorodnych produktów i marek. Przy tak dużym wyborze, klienci oczekują od produktów nie tylko podstawowego zaspokojenia potrzeb, ale dostarczenia dodatkowych wartości i doświadczeń, których inne produkty nie mogą dostarczyć (Nowak, 2016, s. 67). Co więcej, obserwuje się zjawisko społeczne określane jako FOMO (ang. fear of missing out), przejawiające się uczuciem dyskomfortu wynikającym z obawy przeoczenia ważnej informacji, szansy na doświadczenie czy nawiązanie interakcji społecznej (FOMO, http). Dostęp do informacji zwiększa pewność i możliwość argumentacji. Ludzie pewni słuszności swoich przekonań są bardziej skłonni do zakupów i wydają więcej, chętniej wyrażają swoje opinie, rekomendują produkty i marki oraz podejmują próbę przekonywania innych w swoim otoczeniu (Tomala i Rucker, 2016, s. 130). Na tym tle szczególnego znaczenia nabierają blogi. Są one bowiem odpowiedzią na aktualne uwarunkowania zarówno po stronie przedsiębiorstwa, jak i konsumenta. Blog staje się bowiem skutecznym narzędziem dotarcia do potencjalnych klientów, którzy traktują go jako zaufane źródło informacji. Blogosfera ma bardzo duży zasięg. Koncentrując się na blogach prywatnych, ich odbiorcy wykazują się wysokim stopniem lojalności i zaangażowania oraz udostępnianiem treści (Blog (v)Power, http). Daje to szerokie pole do działania $w$ zakresie budowania świadomości produktów oraz pozycjonowania i kreowania wizerunku marek.

\section{Blogi jako narzędzie marketingowe}

Termin „blog” po raz pierwszy użyty został przez Petera Merholza. Inspiracją dla niego okazała się nazwa weblog oznaczająca dziennik sieciowy, wymyślona przez Jorna Bargera (Barska, 2016, s. 132).

Blog z założenia jest uporządkowanym chronologicznie od najświeższego do najstarszego zbiorem oddzielnych komentarzy czy wpisów. Wśród definicji bloga, szczególnie wyraźnie uwypukla jego wyjątkowość definicja S. Streighta (Wright, 2007, s. 223), która ujmuje blog jako płaszczyznę komunikacji, łączności i interakcji, 
umożliwiającą użytkownikom szybkie i łatwe udostępnianie treści na stronie dla szerszej publiczności. Blog przedstawia osobiste poglądy autora i jest w znaczącym stopniu odzwierciedleniem jego osobowości. Szczególną funkcjonalność bloga upatruje się w posiadaniu wszelkich atutów strony internetowej, bez konieczności wnikania w kwestie techniczne (Wright, 2007, s. 223). Umożliwiają archiwizowanie treści, jej kategoryzację oraz komentowanie wpisów przez innych użytkowników. Ważną użytecznością jest tagowanie wpisów, możliwość udostępniania, linkowanie treści, połączenie z innymi mediami społecznościowymi czy stroną internetową. Blog opiera się na dialogu i interakcji (Wright, 2007, s. 217). Ze względu na wiele atutów blogów, swoją szansę biznesową zauważały organizacje, promując marki i produkty poprzez blogi firmowe i prywatne.

Mówiąc o genezie blogów, sięgnąć należy do początków lat 70. XX wieku. Wówczas za sprawą Lesa Earnesta pojawiło się pierwsze protoblogowe narzędzie. Blogi w postaci bardzo zbliżonej do współczesnych zaczęły powstawać w latach 90. XX wieku, a ich twórcami byli Dave Winer, Jorn Barger i Justyn Hall (Barska, 2016, s. 132).

Za pioniera na polskim rynku blogerskim uznaje się Piotra Waglowskiego, autora serwisu vagla.pl (1997 r.). Zaraz po nim w obszarze dziennikarstwa sieciowego powstały blogi kumple.blog.pl oraz raster.blog.pl (Wikipedia, http).

Podstawowy podział blogów, uwzględniający autorstwo bloga, wyróżnia blogi firmowe i prywatne. Najbardziej rozbudowana kategoryzacja blogów ze względu na charakter treści pozwala wyszczególnić blogi (Kos-Łabędowicz, 2015, s. 111-112):

- $\quad$ przeglądowe, nie odzwierciedlające stanowiska autora,

- osobiste, przybierające formę pamiętnika, prezentujące prywatną i indywidualną treść autora,

- notatniki, o charakterze pamiętnika lub przeglądowym,

- $\quad$ instruktażowe, zawierające porady i wskazówki dotyczące konkretnego zagadnienia,

- $\quad$ informacyjne, przybierające formę słownika,

- $\quad$ problemowe, opisujące potencjalne rozwiązania potrzebne do rozstrzygnięcia problemu,

- $\quad$ porównawcze, blogi publikujące zestawienia różnych opinii,

- vlog, blogi wideo,

- krytyczne, wyróżniające się krytyczną oceną wobec danych obszarów tematycznych, ich szczególną wersją są blogi satyryczne,

- „mniemanologiczne”, zachęcające do nawiązania dyskusji w schemacie „Co by było gdyby",

- dyskusyjne, zachęcające innych użytkowników do wyrażenia swojej opinii na dany temat,

- naukowe, poświęcone analizie wybranych zagadnień i zjawisk naukowych,

- $\quad$ analityczne, zajmujące się analizą zjawisk, 
- wywiadowe, publikujące wywiady z osobami znanymi, cenionymi czy ekspertami w pewnych dziedzinach,

- bibliograficzne, przedstawiające sylwetki konkretnych osób,

- trybunowe, zawierające nawet najbardziej kontrowersyjne opinie.

Głównymi atutami blogów są content, interaktywność i otwartość w stosunku do otoczenia. Ważna jest możliwość komentowania i udostępniania postów obserwatorom. $\mathrm{Z}$ tych względów blog staje się bardziej atrakcyjny niż zwyczajne treści promocyjne.

Bloger decyduje o treści, częstotliwości wpisów, ich tematyce i formie (tekst, zdjęcia, film, infografika). Od niego zależy także strona wizualna bloga, dobór szaty graficznej, kolorystyki, styl i rozmiar czcionki, motywy. Ważna jest sama nazwa bloga. Niektóre blogi posiadają także swoje logo.

O atrakcyjności i potencjale bloga, determinującym jego wiarygodność, decydują takie cechy, jak bezpośredniość, nieformalność, obiektywizm i bezstronność. Istotna jest przy tym prostota, regularność wpisów i budowanie zaufania (Mazurek, 2008, s. 20). Formułując uniwersalne rekomendacje w zakresie użyteczności i wzbudzenia zainteresowania blogiem, wskazać można (Pajkert, Dwernicki, 2016, s. 19; Mazurek, 2008, s. 20-22; Handley, Chapman, 2012, s. 170):

- komunikację obrazkową i wideomarketing, wzbogacanie tekstu zdjęciami, filmami wideo, wykresami, infografiką,

- długość wpisów, pozwalającą z jednej strony na wyczerpanie tematu, z drugiej na zainteresowanie, ale nie znużenie czytelnika,

- atrakcyjny lead, trafiony tytuł warunkuje zainteresowanie czytelników i dystrybucję bloga,

- design bloga,

- możliwość subskrypcji,

- możliwość udostępniania postów za pośrednictwem mediów społecznościowych,

- kategoryzację postów, ma pomóc czytelnikowi w odnalezieniu artykułu, który go interesuje w prosty i szybki sposób,

- tagowanie postów, by za pomocą słów kluczy czytelnicy mogli w łatwy sposób odnaleźć interesujące ich posty w wyszukiwarkach internetowych,

- język bloga, preferowane są nieformalne i nieskrępowane wpisy, pozbawione wulgaryzmów, poprawne pod względem stylistycznym, gramatycznym i ortograficznym.

\section{Promocja marki na blogu}

Organizacje, które poważnie myślą o swojej pozycji rynkowej i dążeniu do zdobycia przewagi konkurencyjnej, powinny profesjonalnie zarząazać swoim przekazem 
i wypracować precyzyjny komunikat do otoczenia. Jego podstawą jest indywidualna i wyróżniająca strategia wizerunkowa, która ma podkreślać wyjątkową tożsamość organizacji (Mistewicz, 2011, s. 61).

Ważnym aspektem w kontekście kreowania wizerunku marki poprzez blogi jest emotional branding oparty na budowaniu bliskiej relacji z konsumentem, angażując go w osobisty dialog z marką. Tworzy specyficzną osobowość marki rozumianą jako jej charakter i charyzma, który ma wywołać reakcję emocjonalną (Witek, 2015, s. 91). Emocje są głównym filarem i siłą marek. Emocje odgrywają też ważniejszą rolę $\mathrm{w}$ procesie decyzyjnym niż percepcja. Emocje angażują, percepcja zaś dokonywana jest z pozycji obserwatora (Pogorzelski, 2015, s. 72). Właściwe wyważenie poziomu reprezentatywności i wyróżniania się marki ma duże znaczenie, wpływając na jej wizerunek (Dawar, Bagga, 2015, s. 100).

Marka powinna wywoływać emocje pasujące do jej osobowości i wartości. Może pozytywnie i efektywnie oddziaływać w kierunku swoich odbiorców, którzy w danej sytuacji wykazują z nią interakcję (Kobierzewski, 2016, s. 17).

Marki określają ich użytkowników, ich status i styl życia, by dzięki nim można podkreślić swoją wrażliwość, charakter czy urodę (Stępowski, 2015, s. 99-100).

Wybierając tematykę bloga oraz blogera do współpracy, pamiętać należy, że marki odnoszą sukces, gdy udaje im się przebić w danej przestrzeni kulturowej. Stąd też branding ma nadać marce kulturowe znaczenie (Holt, 2016, s. 98).

Niewątpliwym atutem kreowania wizerunku marki poprzez blogi prywatne, niezależnie od ich tematyki, jest nienachalny i pozbawiony perswazji sposób prezentacji marki. Skromność i dyskretny urok doskonale wpisują się w aktualne trendy i oczekiwania odbiorców oraz opieranie przekazu na content marketingu (Paszkiewicz, 2016, s. 70). Promocja marki przy wykorzystaniu blogów wykorzystuje wszystkie mocne strony content marketingu, tj. (Stępowski, 2016, s. 36-37):

- treść jest informacją, której poszukują odbiorcy, nie jest reklamą i nie budzi zniechęcenia czy wrogości,

- treścią jest każdy materiał (tekst, zdjęcie, wideo), który powinien angażować i zachęcać do komentowania i udostępniania, informować, bawić i dawać impuls do działania,

- potencjalni klienci jako odbiorcy treści postrzegają ją jako bardziej wiarygodną od typowego spotu reklamowego,

- dystrybucja treści poprzez media społecznościowe wpływa na rozpoznawalność marki, jej transparentność i zwiększoną sprzedaż,

- dystrybucja treści poprzez media społecznościowe czyni promocję niskokosztową o dużym zasięgu,

- lepsze pozycjonowanie strony w wyszukiwarkach, także mobilnych, odpowiadające wprost na zapytania internautów. 
Można wskazać uniwersalne cechy bloga, które zwiększają prawdopodobieństwo skutecznego dotarcia marki czy produktu z komunikatem do potencjalnego klienta (Spychalska-Kaczorowska, 2016, s. 23):

- zasięg ilościowy,

- tematyka właściwa dla grupy docelowej,

- pożądany profil czytelnika,

- zawartość treści często publikowanych,

- styl komunikacji zbieżny z wartościami reprezentowanymi przez markę,

- osobiste zaangażowanie blogera w publikowane treści,

- unikalność, rozpoznawalność i wyjątkowość treści,

- jasne zasady współpracy i klarowność umowy z blogerem.

Promowanie marki przy wykorzystaniu kanału komunikacji, jakim jest blog, wymaga sięgania po narzędzia monitoringu marki i analizowania zasobów Internetu. Optymalizacja działań marketingowych w tym zakresie może obejmować kampanie w wyszukiwarce Google AdWords oraz sieci reklamowej Facebook. Ważne staje się także reagowanie poprzez dodawanie komentarzy zawierających linki odsyłające do bloga (Pajkert, Dwernicki, 2016, s. 19).

Rozpoczynając działania promocyjno-wizerunkowe marek na blogach, trzeba zwrócić uwagę na powolne i sukcesywne zdobywanie kapitału zaufania, by wraz $\mathrm{z}$ nabywaniem umiejętności w budowaniu relacji z odbiorcami i we współpracy $\mathrm{z}$ blogerami, tworzyć coraz bardziej atrakcyjne, akceptowalne i angażujące materiały (Spychalska-Kaczorowska, 2016, s. 23). Popularność publikacji rośnie stopniowo i z czasem, a korzyści stąd płynące narastają nieliniowo, jednak artykuły na blogach zachowują wartość przez dłuższy czas (Halligan, Shah, 2011, s. 81).

\section{Znaczenie blogów w kształtowaniu wizerunku marki}

Blogosfera dociera aktualnie w Polsce do ponad 10,7 mln internautów, a 8,6 mln internautów styka się z nią regularnie (Blog (v)power, http). Jej dynamiczny rozwój dotyczący w równym stopniu blogów, jak i vlogów, nie pozostaje bez wpływu na użytkowników Internetu, ich poglądy i zachowania, także percepcję marek i decyzje zakupowe. W szczególności, rosnące zainteresowanie blogami i wskaźniki czytelnictwa sprzyjają ich komercyjnemu wykorzystaniu na rzecz promocji i kreowania wizerunku marek.

W powiązaniu z założonym celem opracowania oraz ujętymi powyżej w artykule rozważaniami na temat blogów, podjęto próbę oceny blogów jako instrumentów komunikacji marketingowej umożliwiających kreowanie wizerunku marek. Rozważania skupiono wokół tezy: blogi mogą istotnie wpływać na percepcję i pozycjonowanie marek, budując ich rynkowy wizerunek. Ocena dokonana została w oparciu 
o badania wtórne. Przedmiotem badań były w szczególności blogi prywatne. Badania obejmowały obszary problemowe dotyczące:

- postawy internautów wobec korzystania z blogów prywatnych,

- użyteczności blogów w procesie podejmowania decyzji o zakupie,

- oceny wpływu blogów na wizerunek marki.

Do oceny blogów jako instrumentów kreowania marek, jako trafne i interesujące wybrano badania zrealizowane na zlecenie Polskiego Stowarzyszenia Blogerów i Vlogerów (PSBV) przez Mobile Institute (wrzesień-październik 2014). Dotyczyły one oceny oddziaływania i siły wpływu blogerów i vlogerów. Zasięg badań objął dwie grupy: internautów czytających blogi i oglądających vlogi $(n=977)$ oraz stałych odbiorców blogów i vlogów $(n=1525)$ (Blog (v)power, http). Ponadto jako źródło danych wykorzystano raport z badań pt. „Rola blogerów i youtuberów we współczesnym świecie". Powstał on w oparciu o badanie zrealizowane w sierpniu 2016 roku na grupie 1409 internautów oraz 123 blogerów i youtuberów. Do badań zastosowano metodę CAWI (Computer-Assisted Web Interview), tj. ankiety elektroniczne emitowane na stronach internetowych oraz $\mathrm{w}$ wysyłce e-mailowej (Rapot blogerów..., http).

Z badań płyną istotne wnioski na rzecz znaczenia blogów w kreowaniu wizerunku marek. Ponad połowa internautów deklaruje, że styka się z treściami zamieszczanymi na blogach lub vlogach, a $45 \%$ deklaruje, że robi to regularnie. Największym zainteresowaniem internautów cieszą się blogi podróżnicze, kulinarne, modowe i kosmetyczne. Wśród vlogów najpopularniejszymi kategoriami są z kolei rozrywka i gry oraz nauka i technologie (Hatalska, http). W tabeli 1 przywołano szczegółowe wyniki ulubionych kategorii blogów.

Blogi i vlogi odgrywają kluczową rolę, informując, ucząc, bawiąc, przedstawiając inny punkt widzenia, budując świadomość czy wspomagając decyzje zakupowe (Blog (v)power, http). Warto zwrócić uwagę, iż wśród osób regularnie czytających blogi, ponad połowa wskazuje na powody związane ze świadomymi zakupami. Zestawienie powodów konsumowania blogów zawarto w tabeli 2.

O znaczeniu blogów w kontekście marketingowych działań na rzecz marek świadczy fakt, iż dla wielu internautów blogi i vlogi stanowią źródło informacji zakupowej. W przypadku internautów deklarujących, że czytają blogi i vlogi jest to $26 \%$ i aż do $72 \%$ wśród stałych odbiorców treści na blogach/vlogach. Warto zaznaczyć, iż dla tej grupy blogi i vlogi wymieniane są wyżej niż opinie rodziny i znajomych (Hatalska, http).

Wyniki badań pokazują, iż internauci traktują blogi i vlogi jako wiarygodne, równorzędne i zaufane źródło informacji zakupowej. Wymieniają nawet po kilkanaście marek, do zakupu których zachęcił lub zniechęcił ich b(v)loger. Deklarują, iż pod wpływem informacji zamieszczonych na blogu/vlogu kupili konkretny produkt (Blog (v)power, http). W tabeli 4 ujęto zachowania zakupowe internautów po kontakcie $\mathrm{z}$ treścią bloga. 
Tabela 1. Ulubione kategorie blogów wśród internautów

\begin{tabular}{|c|c|c|}
\hline Lp. & Kategoria bloga & Zainteresowanie internautów \\
\hline 1. & Podróżnicze & $32 \%$ \\
\hline 2. & Kulinarne & $29 \%$ \\
\hline 3. & Kosmetyki/uroda & $26 \%$ \\
\hline 4. & Naukowe & $22 \%$ \\
\hline 5. & Rozrywka/gry & $20 \%$ \\
\hline 6. & Technologiczne & $20 \%$ \\
\hline 7. & Modowe & $20 \%$ \\
\hline 8. & Kulturalne & $18 \%$ \\
\hline 9. & Moje życie codzienne/osobiste & $17 \%$ \\
\hline 10. & Polityczne & $16 \%$ \\
\hline 11. & Hand made & $15 \%$ \\
\hline 12. & Artystyczne & $13 \%$ \\
\hline 13. & Parentingowe & $12 \%$ \\
\hline 14. & Regionalne & $12 \%$ \\
\hline 15. & Pamiętniki & $12 \%$ \\
\hline 16. & Firmowe & $12 \%$ \\
\hline 17. & Biznes & $11 \%$ \\
\hline
\end{tabular}

Źródło: opracowano na podstawie: Blog (v)power, http

Tabela 2. Powody konsumowania blogów wśród internautów

\begin{tabular}{|c|c|c|}
\hline Lp. & Wyszczególnienie & Zainteresowanie internautów \\
\hline 1. & żeby obejrzeć lub przeczytać coś ciekawego & $80 \%$ \\
\hline 2. & żeby się czegoś nauczyć & $70 \%$ \\
\hline 3. & żeby zdobyć wiedzę w specjalistycznym obszarze & $67 \%$ \\
\hline 4. & żeby kupować bardziej świadomie & $57 \%$ \\
\hline 5. & żeby się rozerwać & $54 \%$ \\
\hline 6. & $\dot{z} e b y$ poznać opinie konkretnych osób & $46 \%$ \\
\hline 7. & $\dot{z} e b y$ być na bieżąco/śledzić trendy & $40 \%$ \\
\hline 8. & żeby wyrobić sobie opinię w danym temacie & $39 \%$ \\
\hline 9. & żeby zbudować/poprawić swój wizerunek & $23 \%$ \\
\hline 10. & $\dot{z} e b y$ wiedzieć, co u znajomych & $8 \%$ \\
\hline 11. & żeby przynależeć do danej społeczności & $7 \%$ \\
\hline
\end{tabular}

Źródło: opracowano na podstawie: Blog (v)power, http 
Tabela 3. Źródła informacji w procesie zakupowym - miejsca poszukiwania informacji o produktach

\begin{tabular}{|c|c|c|}
\hline Lp. & Wyszczególnienie & Wskazania internautów \\
\hline 1. & fora internetowe & $45,2 \%$ \\
\hline 2. & blogi/wideoblogi & $37,4 \%$ \\
\hline 3. & porównywarki cenowe & $32,1 \%$ \\
\hline 4. & opinie rodziny/znajomych & $30,3 \%$ \\
\hline 5. & strony www sprzedawców/producentów & $28,0 \%$ \\
\hline 6. & platformy zakupowe & $26,3 \%$ \\
\hline 7. & profile marek w mediach społecznościowych & $25,8 \%$ \\
\hline 8. & portale internetowe & $25,4 \%$ \\
\hline 9. & serwisy aukcyjne/ogłoszeniowe & $24,4 \%$ \\
\hline 10. & serwisy zawierające opinie & $23,9 \%$ \\
\hline 11. & opinie w mediach społecznościowych & $22,9 \%$ \\
\hline 12. & inne & $0,80 \%$ \\
\hline
\end{tabular}

Źródło: opracowano na podstawie: Raport blogerów..., http

Tabela 4. Postawa respondentów wobec blogów i wideoblogów w kontekście zakupów

\begin{tabular}{|c|c|c|}
\hline Lp. & Wyszczególnienie & $\begin{array}{c}\text { Wskazania internautów } \\
\text { (w skali 0-5) }\end{array}$ \\
\hline 1. & $\begin{array}{c}\text { wierzę opiniom zamieszczanym przez autorów } \\
\text { na blogach lub wideoblogach }\end{array}$ & 4,15 \\
\hline 2. & $\begin{array}{c}\text { uważam, że społeczności zebrane wokół } \\
\text { blogów/wideoblogów mają duży wpływ na biznes }\end{array}$ & 4,11 \\
\hline 3. & zwracam uwagę na reklamy na blogach/wideoblogach & 4,10 \\
\hline 4. & $\begin{array}{c}\text { porady blogerów/youtuberów dotyczące produktów } \\
\text { są często bardziej wartościowe niż porady znajomych }\end{array}$ & 4,10 \\
\hline 5. & $\begin{array}{c}\text { zdarza mi się kupować coś, co rekomenduje/co nosi/ } \\
\text { czego używa bloger lub youtuber }\end{array}$ & 4,05 \\
\hline 6. & $\begin{array}{c}\text { często kieruję się opiniami z blogów/wideoblogów } \\
\text { w kontekście moich zakupów }\end{array}$ & 4,04 \\
\hline
\end{tabular}

Źródło: opracowano na podstawie: Raport blogerów..., http

W ślad za wzrastającą popularnością blogów, wzrasta również aktywność firm w zakresie promocji marek za pośrednictwem znanych i cieszących się dużym zainteresowaniem i autorytetem blogerów. Rankingi najbardziej wpływowych blogerów w Polsce zwracają uwagę na blogi, które warto uwzględnić do współpracy komercyjnej. Ich popularność potwierdza liczba publikacji w mediach oraz wielkość 
ekwiwalentu reklamowego, który byłby kosztem umieszczenia reklamy w danym medium, w takim samym czasie i o takiej samej powierzchni.

Tabela 5. Działania internautów po przeczytaniu lub obejrzeniu bloga

\begin{tabular}{|c|c|c|}
\hline Lp. & Wyszczególnienie & Wskazania internautów \\
\hline 1. & zainteresowanie poruszonym na blogu/wideoblogu tematem & $75 \%$ \\
\hline 2. & spojrzenie na dany problem z innego punktu widzenia & $66 \%$ \\
\hline 3. & poszukiwanie dodatkowych informacji o opisanej marce & $61 \%$ \\
\hline 4. & dodanie marki na listę rozważanych zakupowo & $56 \%$ \\
\hline 5. & zakup danego produktu bądź usługi & $53 \%$ \\
\hline 6. & rezygnacja z zakupu produktu/usługi danej marki & $52 \%$ \\
\hline 7. & skomentowanie wpisu & $46 \%$ \\
\hline 8. & polubienie/udostępnienie wpisu & $41 \%$ \\
\hline 9. & przyłączenie się do komunikowanej akcji & $41 \%$ \\
\hline 10. & zmiana opinii w danym temacie & $36 \%$ \\
\hline 11. & żadne z powyższych & $1 \%$ \\
\hline
\end{tabular}

Źródło: opracowano na podstawie: Blog (v)power, http

Liderami rankingów są dwa blogi modowe: maffashion.pl autorstwa Julii Kuczyńskiej (liczba publikacji medialnych 4861, ekwiwalent reklamowy 39048103 zł) oraz jemerced.com autorstwa Jessiki Mercedes (liczba publikacji medialnych 4011 i ekwiwalent reklamowy 37410312 zł) (Ranking, http). Dziesiątkę najbardziej wpływowych blogerów w Polsce w kolejności alfabetycznej prezentuje tabela 6 .

Tabela 6. Najbardziej wpływowi blogerzy w Polsce w 2015

\begin{tabular}{|c|c|c|c|}
\hline Lp. & Autor bloga & Adres internetowy bloga & Tematyka bloga \\
\hline 1. & Anna i Thomas Alboth & thefamilywithoutborders.com & rodzina/podróże \\
\hline 2. & Marta Dymek & jadlonomia.com & kulinaria \\
\hline 3. & Jessica Mercedes Kirschner & jemerced.com & moda \\
\hline 4. & Konrad Kruczkowski & haloziemia.pl & dziennikarstwo \\
\hline 5. & Julia Kuczyńska & maffashion.pl & moda \\
\hline 6. & Grzegorz Marczak & antyweb.pl & technologia \\
\hline 7. & Przemysław Pająk & spidersweb.pl & technologia \\
\hline 8. & Kamil Pawelski & ekskluzywnymenel.pl & moda \\
\hline 9. & Michał Szafrański & jakoszczedzacpieniadze.pl & finanse \\
\hline 10. & Andrzej Tucholski & andrzejtucholski.pl & biznes/life style \\
\hline
\end{tabular}

Źródło: opracowano na podstawie: Ranking, http 


\section{Podsumowanie}

Praktyka działań organizacji oraz badania rynku pokazują wyraźnie, iż blogi są obecnie ważnym kanałem komunikacji, w szczególności w obszarze kreowania wizerunku marek. Rosnąca liczba internautów i aktywnych czytelników blogów wskazuje na to, iż blogosfera ma duży potencjał komercyjny i znaczącą siłę oddziaływania. Możliwości te jednak są silnie zdeterminowane charakterem bloga, który jest umiejętnym połączeniem aspiracji, umiejętności, autorytetu i charyzmy blogera oraz celów, które w tej przestrzeni chce osiągnąć marka (Kaczorowska-Spychalska, 2016, s. 21). Dobrze prowadzony blog potrafi zapewnić dobrą rozpoznawalność marki, jest pierwszym źródłem informacji o produktach i pod wpływem informacji zamieszczonych na blogu/vlogu nakłonić do zakupu.

\section{BIBLIOGRAFIA}

[1] Barska A., 2016, Reklama wczoraj i dziś, Difin, Warszawa.

[2] DAwAR N., BAGgA C.K., 2015, Zaplanuj skutecznie strategię marki, „Harvard Business Review”, Nr 9.

[3] Halligan B., Shah D., 2010 Inbound marketing. Daj się poznać w Google, serwisach społecznościowych i na blogu, Helion, Gliwice.

[4] Handey A., Chapman C.C., 2011, Treść jest kluczowa. Jak tworzyć powalające blogi, podkasty, wideo, e-booki, webinaria(i inne), Helion, Gliwice.

[5] Holt D., 2016, Marka w mediach społecznościowych, „Harvard Business Review”, Nr 5.

[6] Kaczorowska-Spychalska D., 2016, Jak wybierać z blogosfery, „Marketing w Praktyce”, Nr 10.

[7] Kobierzewski M., 2016, O uszczęśliwianiu w digitalu, „Marketing w Praktyce”, Nr 10.

[8] Kos-ŁaBĘDowicz J., 2015, Internet jako źródło informacji w decyzjach nabywczych konsumenta, C.H. Beck, Warszawa.

[9] Mazurek G., 2008, Blogi i wirtualne społeczności - wykorzystanie w marketingu, Wolters Kluwer, Kraków.

[10] Mazurek G., Tкасzyк J. (red), 2016, The impact of the digital world on management and marketing, Kozminski University, Warszawa.

[11] Mistewicz E., 2011, Marketing narracyjny. Jak budować historie, które sprzedaja, Helion, Gliwice.

[12] Nowak M., 2016, Zaskocz propozycja wartości, „Marketing w Praktyce”, Nr 10.

[13] Pajkert A., Dwernicki J., 2016, Blog dużo może, „Marketing w Praktyce”, Nr 10.

[14] Paszkiewicz R., 2016, Dyskretny urok cyfrowego marketingu, „Marketing w Praktyce”, Nr 10.

[15] Pogorzelski J., 2015, Marka na cztery sposoby. Branding percepcyjny, emocjonalny, społeczny $i$ kulturowy, Wolters Kluwer, Warszawa.

[16] StęPowski R., 2015, Jak osiagnać sukces. Social media, mobile, content marketing, personal branding, Wydawnictwo Roster, Rawa Mazowiecka.

[17] StęPowski R., 2016, Komunikacja marketingowa 2030. Technologiczna rewolucja i mentalna ewolucja, Wydawnictwo Słowa i Myśli, Lublin.

[18] Tormala Z.L., Rucker D.D., 2016, Zwiększ siłe perswazji, „Harvard Business Review”, Nr 2.

[19] Witek E., 2015, Komunikacja wizerunkowa - nowoczesne narzędzia, Wydawnictwo Astrum, Wrocław.

[20] Wright J., 2007, Blogowanie w biznesie, Wydawnictwa Akademickie i Profesjonalne, Warszawa. 


\section{NETOGRAFIA}

[1] Blog (v)power. Wpływ blogów i vlogów na internautów, http://www.psbv.pl/BlogPower_raport. $\operatorname{pdf}(6.12 .2016)$.

[2] FOMO, http://kulturainnowacje.pl/technologie/30-fomo-(fear-of-missing-out) (27.12.2016).

[3] http://hatalska.com/2015/04/09/o-wplywowosci-blogerow-i-vlogerow-na-co-warto-zwrocicuwage-w-raporcie-psbv/ (27.12.2016).

[4] https://pl.wikipedia.org/wiki/Blog (27.12.2016).

[5] Ranking najbardziej wpływowych blogerów 2015 roku, http://jasonhunt.pl/ranking-najbardziej-wplywowych-blogerow-2015-roku/ (29.11.2016).

[6] Rola blogerow i youtuberow we wspótczesnym swiecie, http://blogforumgdansk.pl/downloads/ Raport_Rola_blogerow_youtuberow_we_wspolczesnym_swiecie_BFGdansk.pdf (10.11.2017). 